\title{
Detection of Bartonella sp. in ticks and their small mammal hosts in mangrove forests of Peninsular Malaysia
}

\author{
Asyikha, R. ${ }^{1}$, Sulaiman, N. ${ }^{1}$ and Mohd-Taib, F.S. ${ }^{*}$ \\ ${ }^{1}$ Department of Biological Sciences and Biotechnology, Faculty of Science and Technology, \\ Universiti Kebangsaan Malaysia, 43600 UKM Bangi, Selangor, Malaysia \\ *Corresponding author e-mail: farah_sh@ukm.edu.my \\ Received 11 May 2020; received in revised form 28 August 2020; accepted 1 September 2020
}

\begin{abstract}
Bacteria of the genus Bartonella have been known as emerging zoonotic pathogens for several human diseases including cat scratch disease, Carrion's disease and trench fever. Numerous species of small mammals have been reported to play a role as a suitable reservoir to many pathogenic Bartonella. These infections are thought to be transmitted through blood-feeding arthropod vectors such as ticks, fleas and lice. The purpose of this study is to detect the presence of Bartonella species from tick samples collected from small mammals in mangrove forests of Peninsular Malaysia. Herein, 38 individual ticks and their small mammals host were evaluated for the presence of Bartonella DNA by conventional PCR targeting the 16S rRNA intergenic spacer region (ITS) and partial sequencing of $460 \mathrm{bp}$ from this locususing Bartonella genus-specific primers. Two tick individuals from Dermacentor auratus and Haemaphysalis hystricis collected from Rattus tiomanicus (host), were PCR-positive for Bartonella DNA amplification. No Bartonella amplification was possible in other tick species (Amblyomma sp.). Phylogenetic analysis of ITS fragments demonstrated that the sequences from ticks were closely related to Bartonella phoceensis, a species that has been reported from black rats (Rattus rattus) in Australia. This is the first report of a Bartonella bacteria detected in ticks from small mammals in Malaysia. Further research should be warranted to investigate the transmission of Bartonella and the potential impact of this zoonotic pathogen in animals and humans as this mangrove ecosystem is significant for local economy and tourism.
\end{abstract}

\section{INTRODUCTION}

The genus Bartonella is categorized as Gram-negative bacteria, a slow growing and facultative intracellular parasite which can infect mainly mammalian hosts. Bartonella has been isolated from a variety of small mammals. Various blood-feeding arthropods have been implicated as vectors for Bartonella transmission between hosts and incidental transmission from reservoir hosts to humans (Fenollar et al., 2005; Kosoy et al., 2008; Kabeya et al., 2010). Currently, a total of 35 Bartonella species and three subspecies are recognized in the Taxonomy Database of the National Center for Biotechnology Information (MardosaitèBusaitienè et al., 2019). About 23 Bartonella species or subspecies were acknowledged to infect humans and various animal species including domestic cat, dogs, horses, macaques, bats, cattle, and wild animals (Angelakis and Raoult 2014; Cheslock and Embers 2019). Meanwhile, three Bartonella species including $B$. phoceensis, B. rochalimae, and B. coopersplainsensis particularly infect Rattus rats globally (Buffet et al., 2013; Hayman et al., 2013). Several of these infections have been associated with human disease such as Bartonella bacilliformis causes Carrion's disease and Bartonella quintana acts as the agent of trench fever (Berglund et al., 2010). The role of ticks as vectors of Bartonella is still disputed. Despite multiple reports of molecular detection of Bartonella in ticks, it 
is still unclear if the bacteria detected in ticks is viable or if ticks act as competent vectors or if they simply acquire bacteria in bloodmeals but do not transmit the bacteria to new hosts. Experimental infection studies are still needed to confirm the vector competence of ticks.

Environmental conditions, plasticity of vector competence, and the occurrence of suitable reservoir hosts affect the prevalence of Bartonella species throughout the world (Dybing et al., 2016). Bartonella bacteria have been detected in several wild and domesticated mammalian species, including rodents, carnivores, and ruminants (Saisongkorh et al., 2009). High prevalence of Bartonella infection has been observed in several rodent species, such as Rattus rattus (Ellis et al., 1999), Rattus norvegicus (Gundi et al., 2004), Maxomys spp. (Tea et al., 2004), Mus spp. (Jiyipong et al., 2014), and others (Kosoy and Bai 2019). Nevertheless, we lack complete knowledge of the geographic distribution, host and vector associations, and pathogenicity of some Bartonella species.

Few reports are available of the prevalence of Bartonella species in Malaysia such as, Hou et al. (2018) have detected Bartonella spp. from a small flying fox (Pteropus hypomelanus) which was identified as Bartonella sp. KS013a and KS013b (two different strains) in Peninsular Malaysia. In addition, the DNA of Bartonella henselae and Bartonella clarridgeiae were detected in fleas from domestic dogs and cats (Mokhtar and Tay 2011), meanwhile Bartonella bovis was reported in Haemaphysalis bispinosa ticks collected from beef cattle in Peninsular Malaysia (Kho et al., 2015). Up to date however, no reports of Bartonella available from ticks collected from small mammals. The objective of this study was to examine the presence of Bartonella DNA in ticks and their small mammal hosts in Peninsular Malaysia. This study could contribute to understanding the zoonotic origin of current bartonellosis cases in Malaysia, as well as informing the responsible agencies and communities of the risk of pathogen exposure.

\section{MATERIALS AND METHODS}

\section{Study areas}

The study was carried out in mangroves forests located in three states of Peninsular Malaysia; Terengganu (Kg. Yakyah), Negeri Sembilan (Kg. Sungai Timun) and Perak (Kg. Dew) (Kampung, Kg. = village). These mangroves were situated inland from the coast and facing varying impacts from anthropogenic activities such as in the case of surface run-off pollution from adjacent oil palm plantation and domestic dumps into the river. More details on these anthropogenic activities and the impact on the ecosystem were described in Mohd-Taib et al. (2020). These study sites frequently receive visitors for eco-tourism activities, such as firefly-watching, boat riding, fishing, and birdwatching. In addition, these ecosystems still serve as important sea food product for local communities.

\section{Field samplings}

Field sampling was conducted from December 2017 until February 2018 for six days at each sampling site. A total of one hundred wired mesh cage traps $(28 \mathrm{~cm} \times 15$ $\mathrm{cm} \times 12.5 \mathrm{~cm}$ ) were deployed in each study site. Banana, oil palm fruit and jackfruit were used as bait to lure the small mammals (Bernard et al., 2004). Five stations were established along the river, which stretched as far as one kilometre from the jetty, and cage traps were deployed systematically at each station. Sampling stations were placed in higher elevation areas to minimize the risk of flooding due to tides or nearby rivers, keeping more than $300 \mathrm{~m}$ between traps in the riverbank. The traps were placed on the ground, on fallen logs, and tree stumps (Balete et al., 2009; Rickart et al., 2011). All traps were inspected twice a day at 9.00 am and $5.00 \mathrm{pm}$. Small mammal trapping and handling procedures for small mammals were approved by the animal research ethics committee at Universiti Kebangsaan Malaysia, Malaysia (FST/2020/FARAH SHAFAWATI/16-JAN./1080-FEB.-2020-FEB.2022-NAR-CAT2). 


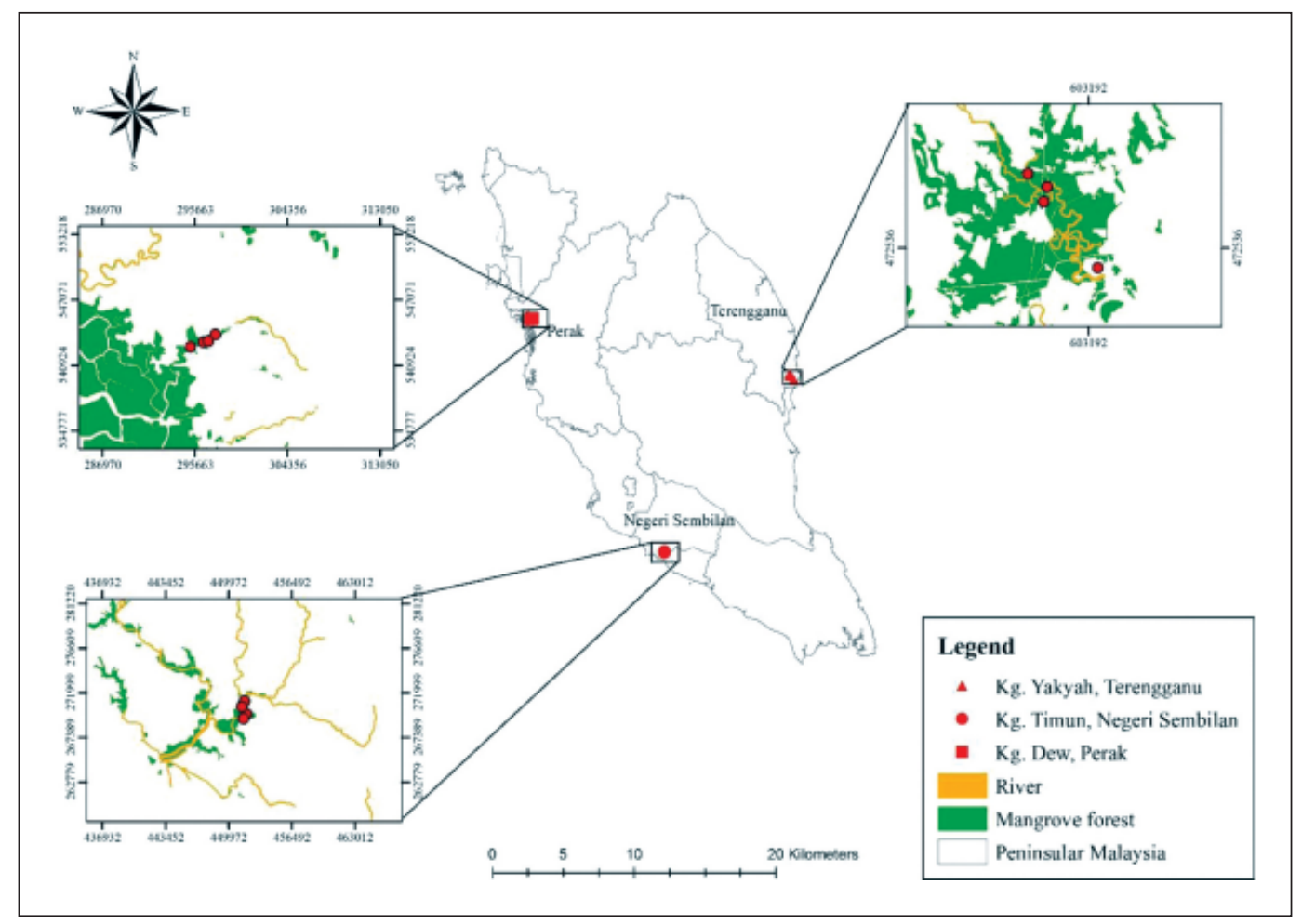

Figure 1. Location of mangrove areas at Kg. Dew, Perak; Kg. Yakyah, Terengganu; and Kg. Timun, Negeri Sembilan in Peninsular Malaysia.

\section{Species identification of small mammals}

Every small mammal individual captured was given the anaesthetic injection using Zoletil ${ }^{\circledR} 100$ (Massolo et al., 2003) with a volume between $0.1 \mathrm{~mL}$ and $0.3 \mathrm{~mL}$ according to the animal weight. After gaining consciousness, they were given the supplemental food and then released back to their captured sites. The morphological identification for each individual species was performed followed Francis (2008). Standard morphological measurements were recorded including length of tail, whole body, head, ears, and foot patch by using a Vernier calliper and ruler. Furthermore, other physical features such as hair color were noted to help in the identification process. A small cut from the tip of the tail (tissue sample) was taken and placed into $1.5 \mathrm{~mL}$ cryovial tube for molecular identification work in order to confirm the species. The tube was stored in a liquid nitrogen tank for transportation to the laboratory after collection in the field.

\section{Collection and morphological identi- fication of ticks}

Ticks were collected using sterile stainlesssteel tweezers from the skin, ears and fur of the rodents. Individual ticks from the same host were placed in a single micro vial tube, labelled and recorded in the datasheet. The vial tubes were then stored in liquid nitrogen before being processed in the laboratory. Each tick was surface sterilized with $70 \%$ ethanol solution prior to observation, followed by washing in sterile distilled water (Carpi et al., 2011). Ticks were then observed under a stereo microscope (Motic SMZ-168 Stereo Zoom microscope) (Motic, Hong Kong) to examine the features and physical characteristics. Individual ticks were morphologically identified to the genus level classified based on the developmental stage and sex using published taxonomic keys (Yamaguti et al., 1971; Baker 1999; Walker et al., 2003), and molecularly identified to the species level by using specific primer. 
DNA extraction and PCR amplification of small mammals and ticks

The ticks and tissue sample of hosts were subjected to molecular investigation, after the examination steps. DNA Extraction using HiYield Plus Genomic DNA Mini Kit (Real Biotech Corporation (RBC), Taiwan) was carried out according to the manufacturer's protocol. DNA of ticks and tails tissue of small mammals were extracted by adding $500 \mu \mathrm{L}$ of phosphate buffer saline (PBS) to the sample. Then, $200 \mu \mathrm{L}$ of QGT Buffer and $20 \mu \mathrm{L}$ of Proteinase $\mathrm{K}$ was added and the samples were incubated after vortexing at $60^{\circ} \mathrm{C}$ overnight until the sample lysate became clear. The DNA extracted was stored in $-20^{\circ} \mathrm{C}$ for further analysis.

PCR amplification for tick was performed with a pair of specific primer set designed by Black and Piesman (1994), namely 16S+1 (5'-CTGCTCAATGATTTTTT AAATTGCTGTGG-3') and 16S-1 (5'-CCGGTC TGAACTCAGATCAAGT-3'). PCR reaction was conducted in a total volume of $35 \mu \mathrm{L}$ containing $13 \mu \mathrm{L}$ of $2 \times$ Taq PCR Master Mix (Lucigen, US), $10 \mu \mathrm{L}$ of nuclease free water, $1 \mu \mathrm{L}$ of $0.5 \mu \mathrm{mol} / \mathrm{L}$ of each primer, and $5 \mu \mathrm{L}$ of DNA template. The PCR was conducted using an Alpha Cycler PCRmax machine (PCRmax, UK). The PCR amplification program for 16S rDNA gene was performed under the following condition: initial denaturation at $95^{\circ} \mathrm{C}(5 \mathrm{~min})$, followed by 10 cycles of denaturation at $92^{\circ} \mathrm{C}(1 \mathrm{~min})$, $48^{\circ} \mathrm{C}(1 \mathrm{~min})$ and $72^{\circ} \mathrm{C}$ for $(1.5 \mathrm{~min})$. Next, continued with 32 cycles of $92^{\circ} \mathrm{C}(1 \mathrm{~min})$, $54^{\circ} \mathrm{C}(35 \mathrm{sec}), 72^{\circ} \mathrm{C}(1.5 \mathrm{~min})$ and followed by final extension at $72^{\circ} \mathrm{C}(7 \mathrm{~min})$.

Meanwhile, for DNA barcoding on small mammal species, the cytochrome c oxidase 1 (COI) gene was amplified by using primers of BatL5310 (5'-CCTACTC RGCCATTTTACCTATG-3') for the forward strand and R6036R (5'-ACTTCTGGGTG TCCAAAGAATCA-3') for the reverse strand (Robins et al., 2007; Ivanova et al., 2012). The PCR protocols used 35 cycles of denaturation, annealing, and elongation: $94^{\circ} \mathrm{C}(30 \mathrm{sec}), 55^{\circ} \mathrm{C}(40 \mathrm{sec})$ and $72^{\circ} \mathrm{C}(90$ sec). The purified PCR products were sequenced, and the final alignment contained 697 nucleotides for the COI gene.
In all cases, nuclease free water was used as a negative control to replace the DNA template. After that, the amplified products were visualized in $1.0 \%$ agarose gel (TAE buffer) electrophoresis and viewed under an ultraviolet trans-illuminator after staining with gel DNA stain (Florosafe stain). The DNA purification and further sequencing analysis were performed by MyTACG Bioscience Enterprise.

\section{Bartonella ITS (16S-23S ribosomal RNA intergenic spacer) genus PCR amplification}

Bartonella genus screening was carried out as previously described (Maggi and Breitschwerdt, 2005). PCR amplification of the Bartonella ITS region was performed in all 38 tick samples that were collected from 15 individual rodents, using oligonucleotides with the forward primer BA325s: 5'-CTTC AGATGATGATCCCAAGCCTTCTGGCG-3' and BA1100as: 5'-GAACCGACGACCCCC TGCTTGCAAAGCA-3' as the reverse primer. PCR amplification was performed in a $25 \mu \mathrm{L}$ final volume reaction containing $12.5 \mu \mathrm{L}$ of $2 \times$ Taq PCR Master Mix (Lucigen, US), 0.75 $\mu \mathrm{L}$ of $30 \mu \mathrm{M}$ of each primer, $6 \mu \mathrm{L}$ of nuclease free water, and $5 \mu \mathrm{L}$ of DNA template from each sample. PCR negative control was prepared using nuclease free water. PCR was conducted using an Alpha Cycler PCRmax machine (PCRmax, UK) under the following conditions: a single hotstart cycle at $95^{\circ} \mathrm{C}$ for 2 min followed by 55 cycles of denaturing at $94^{\circ} \mathrm{C}(15 \mathrm{sec})$. Next, annealing procedure was conducted at $66^{\circ} \mathrm{C}(15 \mathrm{sec})$ and followed by extension at $72^{\circ} \mathrm{C}(18 \mathrm{sec})$. Amplification was accomplished by an additional cycle at $72^{\circ} \mathrm{C}(1 \mathrm{~min})$, and PCR products were analysed by $1.0 \%$ agarose gel electrophoresis and viewed under an ultraviolet transilluminator after staining with FloroSafe DNA stain (alternative stain). The DNA purification and further sequencing analysis were completed by MyTACG Bioscience Enterprise. PCR detection of Bartonella ITS was also performed on the host individuals, using the tissue samples. 


\section{Sequencing and BLAST analysis}

The length of few sequences on small mammal tail samples, ticks and Bartonella bacteria were trimmed and edited manually to eliminate regions that were only available for some nucleotide sequences. The alignment of sequences was exported as FASTA format files by using MEGA (Molecular Evolutionary Genetic Analysis) software version 7 (Kumar et al., 2016). The obtained results were then compared with other available sequences in the GenBank database using analysis of BLAST (http:// www.ncbi.nlm.gov/BLAST/) for confirmation of ticks, small mammals and Bartonella species. Besides that, this tool revealed the prompt comparison of query sequences with database sequences leading to identification of species (Mitler et al., 2010).

\section{Phylogenetic analysis}

The phylogenetic tree for all sequences were achieved by neighbor-joining (NJ) based on Kimura two-parameter model (K2) to conclude the relationships within and between small mammal and tick species. Node support across the phylogenetic tree was estimated using 1000 bootstrap replicates. Echinosorex gymnura (GenBank accession no. MK112014) was used as an outgroup for small mammals and Escherichia coli strain BzDS03 (JF961337) was used as an outgroup for Bartonella bacteria. An examination of the pairwise sequence comparison was generated using MEGA software version 7. In addition, a total of 10 Bartonella sequences that available from GenBank were employed in the phylogenetic analysis as shown in Table 1.

\section{RESULTS}

A total of 94 small mammals belonging to six species (Rattus tiomanicus, Rattus R3, Maxomys whiteheadi, Sundamys muelleri, Callosciurus notatus and Tupaia glis), three family (Muridae, Sciuridae and Tupaiidae) and two orders were captured from three different mangrove sites. From that number, 15 individuals host were infested with ticks. Table 2 documented the list of representative small mammal host and the BLAST results from the GenBank. In general, the percent similarity between small mammal sequences and the closest match in NCBI GenBank was between $98 \%$ to $100 \%$.

Phylogenetic relationships based on the alignment of $\mathrm{CO} 1$ gene were performed to analyse the phylogenetic status of the small mammal sequences in this study (Figure 2). This phylogenetic tree showed that four species from family Muridae were clustered together, which R. tiomanicus and Rattus R3 shared 100\% bootstrap value. Meanwhile, T. glis and $C$. notatus were clustered separately with $0.25 \%$ of genetic distance value. In this analysis, Echinosorex gymnura was used as an outgroup and was highly separated from another five major clades.

Table 1. DNA sequences obtained from GenBank employed in the phylogenetic analysis

\begin{tabular}{clcc}
\hline No & Bacteria species & Locality & GenBank accession no. \\
\hline 1 & Bartonella henselae & Brazil & KU291316 \\
2 & Bartonella henselae & Malaysia & KT318619 \\
3 & Bartonella phoceensis & Australia & KU170606 \\
4 & Uncultured Bartonella sp. & Australia & KU240396 \\
5 & Uncultured Bartonella sp. & Australia & KU240400 \\
6 & Uncultured Bartonella sp. & Australia & KU240402 \\
7 & Uncultured Bartonella sp. & Australia & KU240406 \\
8 & Uncultured Bartonella sp. & Australia & KU240410 \\
9 & Uncultured Bartonella sp. & Australia & KU240414 \\
10 & Uncultured Bartonella sp. & Australia & KU240416 \\
11 & Bartonella bacilliformis & Korea & JN810857 \\
12 & Bartonella sp. & Taiwan & FJ667566 \\
\hline
\end{tabular}


Table 2. List of representative host species and BLAST results from the GenBank

\begin{tabular}{|c|c|c|c|c|}
\hline \multirow{2}{*}{ ID code } & \multirow{2}{*}{ Mangrove area } & \multicolumn{2}{|c|}{ Host species (Identification) } & \multirow{2}{*}{$\begin{array}{c}\text { Similarity } \\
\text { with } \\
\text { GenBank }\end{array}$} \\
\hline & & Morphology & Molecular & \\
\hline PKY010 & \multirow{8}{*}{$\begin{array}{l}\text { Kg. Yak Yah, } \\
\text { Terengganu }\end{array}$} & Rattus sp. & Rattus tiomanicus & $98 \%$ \\
\hline PKY012 & & Rattus sp. & Rattus tiomanicus & $98 \%$ \\
\hline PKY015 & & Rattus sp. & Rattus tiomanicus & $98 \%$ \\
\hline PKY016 & & Rattus sp. & Rattus tiomanicus & $98 \%$ \\
\hline PKY002 & & Rattus rattus & Rattus R3 & $99 \%$ \\
\hline PKY009 & & Rattus rattus & Rattus R3 & $98 \%$ \\
\hline PKY014 & & Rattus rattus & Rattus R3 & $98 \%$ \\
\hline PKY004 & & Maxomys whiteheadi & Maxomys whiteheadi & $99 \%$ \\
\hline STM003 & \multirow{7}{*}{$\begin{array}{l}\text { Kg. Sg. Timun, } \\
\text { N. Sembilan }\end{array}$} & Rattus sp. & Rattus tiomanicus & $98 \%$ \\
\hline STM026 & & Rattus sp. & Rattus tiomanicus & $98 \%$ \\
\hline STM032 & & Rattus sp. & Rattus tiomanicus & $99 \%$ \\
\hline STM001 & & Tupaia glis & Tupaia glis & $99 \%$ \\
\hline STM014 & & Tupaia glis & Tupaia glis & $99 \%$ \\
\hline STM015 & & Callosciurus notatus & Callosciurus notatus & $99 \%$ \\
\hline STM020 & & Callosciurus notatus & Callosciurus notatus & $99 \%$ \\
\hline KDM016 & \multirow{10}{*}{ Kg. Dew, Perak } & Rattus sp. & Rattus tiomanicus & $99 \%$ \\
\hline KDM023 & & Rattus sp. & Rattus tiomanicus & $98 \%$ \\
\hline KDM032 & & Rattus sp. & Rattus tiomanicus & $99 \%$ \\
\hline KDM042 & & Rattus sp. & Rattus tiomanicus & $99 \%$ \\
\hline KDM006 & & Sundamys muelleri & Sundamys muelleri & $99 \%$ \\
\hline KDM036 & & Sundamys muelleri & Sundamys muelleri & $99 \%$ \\
\hline KDM037 & & Sundamys muelleri & Sundamys muelleri & $98 \%$ \\
\hline KDM038 & & Sundamys muelleri & Sundamys muelleri & $99 \%$ \\
\hline KDM004 & & Tupaia glis & Tupaia glis & $99 \%$ \\
\hline KDM012 & & Tupaia glis & Tupaia glis & $100 \%$ \\
\hline
\end{tabular}

A total of 38 individuals of ticks (all female) were collected from 15 small mammals' individuals. These ticks were identified as Ixodes granulatus $(\mathrm{n}=2)$, Amblyomma cordiferum $(\mathrm{n}=26)$, Dermacentor atrosignatus $(\mathrm{n}=5)$, Dermacentor auratus $(\mathrm{n}=4)$ and Haemaphysalis hystricis $(n=1)$ by a combination of morphological features and molecular analysis confirmed by BLAST. Bartonella ITS was detected in 2 of 38 ticks (5.26\% prevalence) collected from the small mammal hosts. Both positive ticks were adult stage. These ticks were identified as Dermacentor auratus and Haemaphysalis hystricis, but other ticks species from various other hosts were not positive for this bacteria. Both positive ticks were collected from Rattus tiomanicus, where $D$. auratus were found in Kg. Yakyah, whereas, Haemaphysalis hystricis were found in Kg. Sungai Timun. None of the ticks in Kg. Dew were found to be positive for Bartonella. Both Rattus tiomanicus host individuals that produced positive ticks were also PCR-positive for Bartonella ITS from tissue samples.

To discover the most closely related homolog for the Bartonella species that may be existing in the tick samples, we performed sequence analysis of PCR amplicons obtained from two representative ticks and hosts sample and compared these sequences with the available reference sequences of Bartonella in the GenBank database. The ITS gene amplified from these tick specimens using the primers BA325s and BA1100as were found to be approximately $460 \mathrm{bp}$ in length. The partial ITS sequences of Bartonella sp. were aligned to those of two tick species from the nucleotide database at NCBI.

Table 3 listed the four ITS sequences of bacterial Bartonella submitted to NCBI database. BLAST queries using sequences obtained from ticks and their hosts showed that both sequences were most closely 


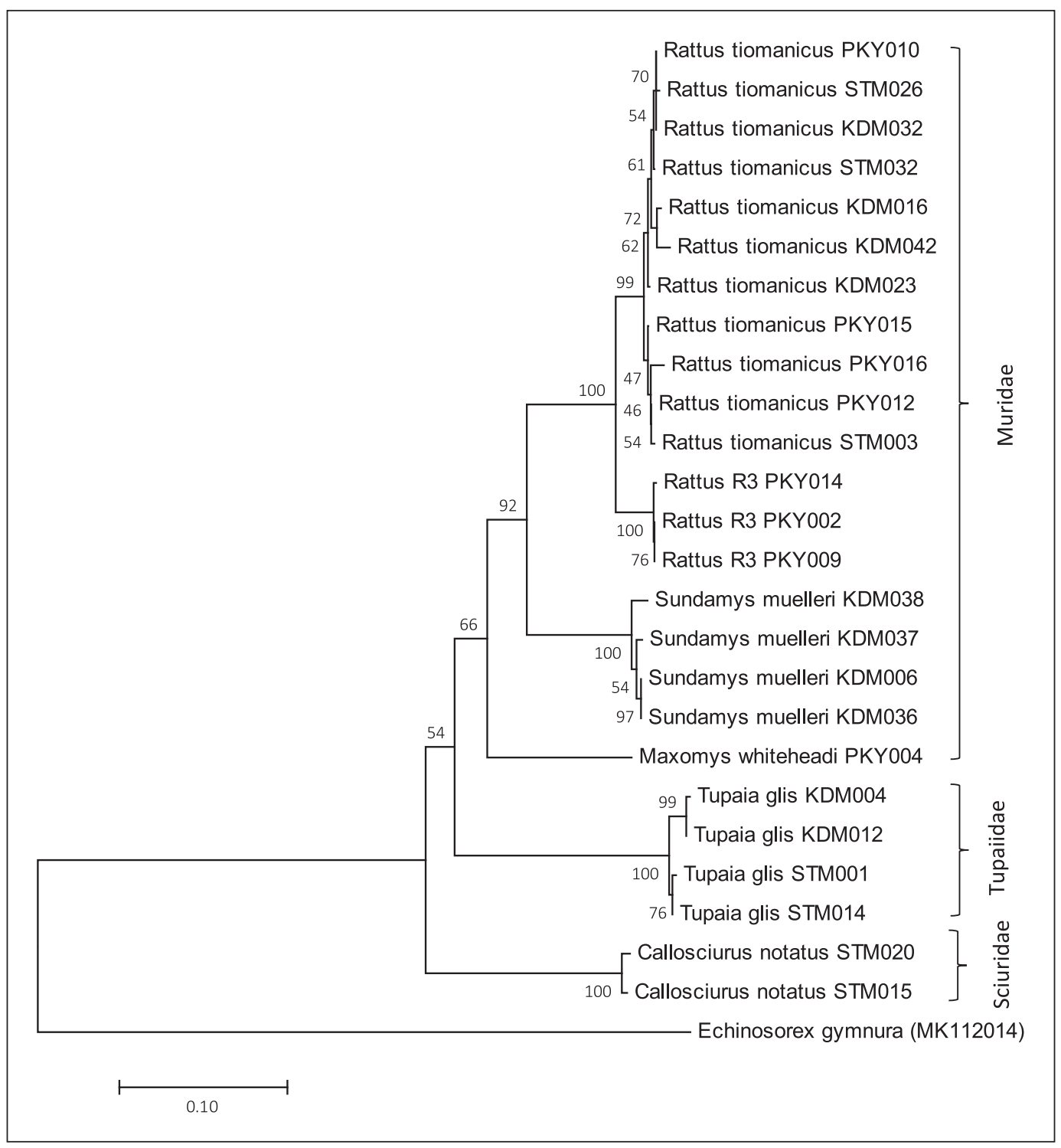

Figure 2. Phylogenetic relationship of small mammal's species based on COI gene sequences. The Neighbor-Joining tree was constructed based on Kimura two-parameter model (K2) to conclude the relationships within and between small mammal's species. Echinosorex gymnura was used as an outgroup for this study.

Table 3. List of sequences submitted to NCBI database with GenBank accession numbers

\begin{tabular}{lccccc}
\hline ID code & Mangrove area & Tick species & Bacteria & $\begin{array}{c}\text { Percent } \\
\text { sequence } \\
\text { identity }\end{array}$ & $\begin{array}{c}\text { GenBank } \\
\text { accession } \\
\text { no. }\end{array}$ \\
\hline PKY016-01 & Kg. Yak Yah, & Dermacentor auratus & Bartonella sp. & $99.0 \%$ & MT792313 \\
PKY016 & Terengganu & R. tiomanicus & Bartonella sp. & $98.0 \%$ & MT925967 \\
\hline STM016-01 & Kg. Sg. Timun, & Haemaphysalis hystricis & Bartonella sp. & $97.8 \%$ & MT809005 \\
STM016 & N. Sembilan & R. tiomanicus & Bartonella sp. & $97.9 \%$ & MT925968 \\
\hline
\end{tabular}


related to Bartonella sp. 161210, a strain of Bartonella phoceensis, with $99 \%$ and $97 \%$ similarity.

Next, phylogenetic relationships based on the alignment of ITS sequences were performed to analyse the phylogenetic status of the Bartonella sequences in this study (Figure 3). From this result, both Bartonella sp. from ticks and their hosts in each study site were equivalent with each other. This phylogenetic tree showed that Bartonella sp. 16120 strain (PKY016-01) in tick and host sample (Rattus tiomanicus (PKY016)) were clustered together with Bartonella phoceensis and uncultured Bartonella sp. with a bootstrap value of $100 \%$. From this study, Bartonella sp. 16120 strain (PKY01601) was closely related to Bartonella phoceensis and uncultured Bartonella sp. whereas, there was slightly difference about $0.1 \%$ genetic distance with another Bartonella sp. 16120 strain (STM016-01). Besides that, PKY016-01 sample showed high percentage of sequence identity with $B$. phoceensis and uncultured Bartonella sp. While, for
Bartonella sp. 16120 strain (STM016-01) was slightly distant with other Bartonella sequence with only $0.1 \%$ distant. Moreover, most of Bartonella sequences (including STM016-01 and PKY016-01) were distantly grouped with $B$. henselae (KU291316 and KT318619), corresponding with a lower percentage identity compared on the DNA comparison which presented in Figure 3.

\section{DISCUSSION}

From this study, we discovered the presence of Bartonella species in ticks from Dermacentor auratus and Haemaphysalis hystricis at $5.26 \%$ prevalence, collected from Rattus tiomanicus in two mangrove sites of Peninsular Malaysia. To date, this is the first report of Bartonella sp. 16120 strain from ticks of small mammals in Malaysia, which closely related to Bartonella phoceensis documented in rodents from Australia and in ticks collected from cattle in Malaysia. Recently, B. phoceensis have

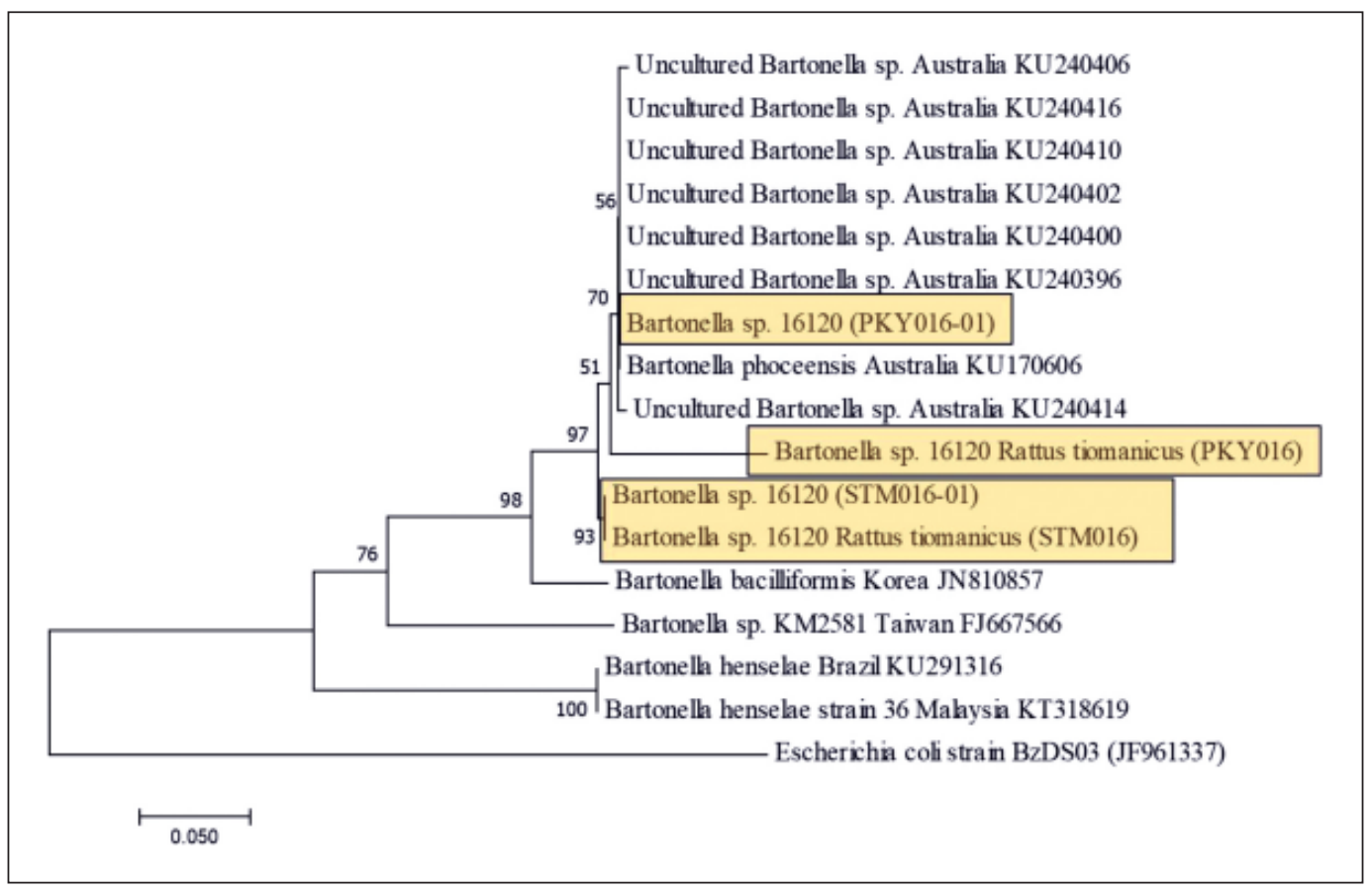

Figure 3. Phylogenetic relationship of Bartonella sp. with other bacteria species based on ITS (16S-23S rRNA) sequences. The Neighbor-Joining tree was constructed based on Kimura twoparameter model (K2) to conclude the relationships within and between Bartonella species. Escherichia coli strain BzDS03 was used as an outgroup for this study. 
been reported firstly in Malaysia from synanthropic rodents (Low et al., 2020). Previously, B. phoceensis also have been reported to be found in rodents in Asia country including Indonesia, Japan, Singapore, Taiwan, and Thailand (Billeter et al., 2008, Tsai et al., 2010). Hence, signifying that these genospecies may not only limited to Southeast Asia (Gundi et al., 2004), but also Australasia. In addition, the PCR positive result also appeared in their small mammal host, which is might indicate that the hosts were carrying the same bacteria as the ticks which had acquired the bacteria from the host in a recent bloodmeal (Pichon et al., 2005). However, from the phylogenetic analysis, Bartonella henselae which is a causative agent of cat scratch disease was distantly related to Bartonella sp. 16120 strain. Nonetheless, there was a slightly difference with Bartonella bacilliformis (Carrion's disease) reported from Korea.

Although, our study only used a partial of ITS gene for phylogenetic analysis, this gene has been revealed to be a reliable implement for distinguishing between Bartonella genotypes that closely related to Bartonella strains found in other geographical areas (La Scola et al., 2003). Prevalence of Bartonella infections among ticks varies considerably in different parts of the world. For instance, it was documented in Ixodes pacificus and I. scapularis in the US, I. ricinus in the Netherlands and Italy, and I. persulcatus ticks in Western Siberia (Holmberg et al., 2003; Kosoy et al., 1997; Tea et al., 2004). Another study reported that Bartonella grahamii strains detected from 10 rodent species, with different host specificity in geographic site; low host specificity in Europe and strict host specificity in North America and Asia (Inoue et al., 2009). Kabeya et al. (2010) found identical Bartonella sp. in ticks from the same small mammal hosts, indicating that these bacteria could be originated from the host's blood.

Due to the location of the sampling areas which involved occupational activities, such as fishing, trekking, and logging, there is high potential of human contact with the infected tick vectors, as well as the small mammal hosts itself. Therefore, implying the possibility of transmission of these bacteria to human (Regier et al., 2016). Apart from that, tourism activities synonym to this area which include firefly and bird watching posed threat to the visitors. On another instance, the life-stages of ticks which include egg, larvae, nymph and adult more likely acquire different animal hosts (Kho et al., 2015). According to Chang et al. (2001), ticks in larvae and nymph phases primarily prefer feed on small mammals and reptiles in which serve as a vital source of infection. Subsequently, the nymphal or adult ticks could then spread Bartonella sp. to large animals and probably directly to human through biting ticks. Besides, the small mammal hosts which recognized as preferred hosts of the adult ticks are the main factors of tick abundance in tick-permissive habitats (Gray et al., 1992). In addition, these bacteria could also be transmitted by other arthropod ectoparasites like fleas, mites and lices as mentioned in Theonest et al. (2019).

Bartonella species have been recognized as significant sources of human febrile disease in several global scale but there still has been little study toward human health of bartonellosis (Halliday et al., 2015). To date, vector-competence of some of arthropods vector has not been completed for Bartonella spp. transmission and are suspected in many more (Regier et al., 2016). The discovery of Bartonella genotypes that are most similar to B. phoceensis and uncultured Bartonella sp. reference DNA sequences from small mammals trapped in Peninsular Malaysia infer great possibility of Bartonella infection upon unknown proportion of febrile illnesses in this region. This study also provided a little evidence regarding the prevalence of Bartonella species in ticks and their hosts from mangrove areas as well as eco-tourism areas in Malaysia.

Detection of Bartonella sp. in ticks species from small mammals in the mangroves forests imply that residents and visitors in that area are exposed to tick bites or even the adult stage of the ticks life cycle which inhabited around mangrove forest. We demonstrated that the existence of Bartonella 
DNA in D. auratus and H. hystricis indicating these ticks should be added to the growing list of potential tick vectors to disclose their possible roles in zoonotic disease. However, there is a possibility of the pathogen to be transmitted to other ticks' species and other small mammals through blood-transmission. Subsequently, there is possibility of transmission to human which is in contact with mangrove habitat, regardless for occupational or tourism purposes. Thus, precautions need to be taken to avoid tick bites. Further examination is necessary to investigate the viable transmission of the Bartonella pathogens and the impact of this zoonotic infection in animals and human.

Acknowledgments. We would like to thank Tenaga Nasional Berhad Research (TNBR) for providing funds through research grant ST-2017-013. We extend our gratitude to the state agencies permitting the research work in the mangrove areas, field assistants and members of Wildlife Disease and Ecology Research group (WildDER), Universiti Kebangsaan Malaysia.

\section{REFERENCES}

Angelakis, E. \& Raoult, D. (2014). Pathogenicity and treatment of Bartonella infections. International Journal of Antimicrobial Agents 44(1): 16-25.

Baker, A.S. (1999). Mites and ticks of domestic animals. An identification guide and information source. London: The Stationery Office.

Balete, D.S., Heaney, L.R., Josefa Veluz, M. \& Rickart, E.A. (2009). Diversity patterns of small mammals in the Zambales Mts., Luzon, Philippines. Mammalian Biology - Zeitschrift für Säugetierkunde 74(6): 456-466.

Berglund, E.C., Ellegaard, K., Granberg, F., Xie, Z., Maruyama, S., Kosoy, M.Y., Birtles, R.J. \& Andersson, S.G. (2010). Rapid diversification by recombination in Bartonella grahamii from wild rodents in Asia contrasts with low levels of genomic divergence in Northern Europe and America. Molecular Ecolology 19: 2241-2255.

Bernard, H., Mohd Yusah, K., Yasuma, S. \& Kimsui, L. (2004). A survey of the nonflying small mammals at several elevations and around Crocker Range Park. Crocker Range Scientific Expedition 2002: 113-130.

Billeter, S.A., Levy, M.G., Chomel, B.B. \& Breitschwerdt, E.B. (2008). Vector transmission of Bartonella species with emphasis on the potential for tick transmission. Medical and Veterinary Entomology 22(1): 1-15.

Black, W.C. \& Piesman, J. (1994). Phylogeny of hard- and soft-tick taxa (Acari: Ixodidae) based on mitochondrial $16 \mathrm{~S}$ rDNA sequences. Proceedings of the National Academy of Sciences of the United States of America 91: 1003410038.

Brahma, R.K., Dixit, V., Sangwan, A.K. \& Doley, R. (2014). Identification and characterization of Rhipicephalus (Boophilus) microplus and Haemaphysalis bispinosa tick (Acari: Ixodidae) of North East India by ITS2 and 16S rDNA and morphological analysis. Experimental and Applied Acarology 62: 253265.

Breitschwerdt, E.B. \& Kordick, D.L. (2000). Bartonella infection in animals; carriership, reservoir, potential, pathogenicity, and zoonotic potential for human infection. Clinical Microbiology Reviews 13: 428-438.

Buffet, J.P., Kosoy, M. \& Vayssier-Taussat, M. (2013). Natural history of Bartonella infecting rodents in light of new knowledge on genomics, diversity and evolution. Future Microbiology 8: 11171128.

Carpi, G., Cagnacci, F., Wittekindt, N.E., Zhao, F., Qi, J., Tomsho, L.P. Drautz, D.I., Rizzoli, A. \& Schuster, S.C. (2011). Metagenomic profile of the bacterial communities associated with Ixodes ricinus ticks. PLoS One 6(10): e25604. 
Chang, C.C., Chomel, B.B., Kasten, R.W., Romano, V. \& Tietze, N. (2001). Molecular evidence of Bartonella spp. in questing adult Ixodes pacificus ticks in California. Journal of Clinical Microbiology 39(4): 1221-1226.

Cheslock, M.A. \& Embers, M.E. (2019). Human bartonellosis: an underappreciated public health problem? Tropical Medicine and Infectious Disease 4(2): 69.

Dybing, N.A., Jacobson, C., Irwin, P., Algar, D. \& Adams, P.J. (2016). Bartonella species identified in rodent and feline hosts from island and mainland western Australia. Vector-Borne and Zoonotic Diseases 16: 238-244.

Ellis, B.A., Regnery, R.L., Beati, L., Bacellar, F., Rood, M., Glass, G.G., Marston, E., Ksiazek, T.G., Jones, D. \& Childs, J.E. (1999). Rats of the genus Rattus are reservoir hosts for pathogenic Bartonella species: an Old World origin for a new world disease? The Journal of Infectious Diseases 180(1): 220-224.

Felsenstein, J. (1985). Confidence limits on phylogenies: An approach using the bootstrap. Evolution 39: 783-791.

Fenollar, F., Sire, S. \& Raoult, D. (2005). Bartonella vinsonii subsp. Arupensis as an agent of blood culture-negative endocarditis in a human. Journal of Clinical Microbiology 43: 945-947.

Francis, C.M. (2008). A Guide to The Mammals of Southeast Asia. New Jersey, Princeton University Press, pp.328-346.

Gray, J.S., Kahl, O., Janetzki, C. \& Stein, J. (1992). Studies of the ecology of Lyme disease in a deer forest in County Galway, Ireland. Journal of Medical Entomology 29: 915-920.

Gundi, V.A.K.B., Davoust, B., Khamis, A., Boni, M., Raoult, D. \& La Scola, B. (2004). Isolation of Bartonella rattimassiliensis sp. nov. and Bartonella phoceensis sp. nov. from European Rattus norvegicus. Journal of Clinical Microbiology 42: 3816-3818.
Halliday, J.E., Allan, K.J., Ekwem, D. Cleaveland, S., Kazwala, R.R. \& Crump, J.A. (2015). Endemic zoonoses in the tropics: a public health problem hiding in plain sight. Veterinary Record 176(9): 220-225.

Hayman, D.T.S., McDonald, K.D. \& Kosoy, M.Y. (2013). Evolutionary history of ratborne Bartonella: the importance of commensal rats in the dissemination of bacterial infections globally. Ecology and Evolution 3(10): 3195-3203.

Holmberg, M., Mills, J.N., Mcgill, S., Benjamin, G. \& Ellis, B.A. (2003). Bartonella infection in sylvatic small mammals of central Sweden. Epidemiology and Infection 130: 149-157.

Hou, S.L., Koh, F.X., Nuryana, I., Sitam, F.T. \& Tay, S.T. (2018). Molecular detection of Bartonella spp. in Malaysian small flying foxes (Pteropus hypomelanus). Tropical Biomedicine 35(1): 293-299.

Inoue, K., Maruyama, S., Kabeya, H., Hagiya, K., Izumi, Y., Une, Y. \& Yoshikawa, Y. (2009). Exotic small mammals as potential reservoirs of zoonotic Bartonella spp. Emerg Infect Dis 15(4): 526-532.

Ivanova, N.V., Clare, E.L. \& Borisenko, A.V. (2012). DNA Barcoding in Mammals. In: Kress W., Erickson D. (eds) DNA Barcodes. Methods in Molecular Biology (Methods and Protocols), vol 858. Humana Press, Totowa, NJ.

Jiyipong, T., Jittapalapong, S., Morand, S. \& Rolain, J-M. (2014). Bartonella species in small mammals and their potential vectors in Asia. Asian Pacific Journal of Tropical Biomedicine 4(10): 757-767.

Kabeya, H., Colborn, J.M., Bai, Y. Lerdthusnee, K., Richardson, J.H., Maruyama, S. \& Kosoy, M.Y. (2010). Detection of Bartonella tamiae DNA in ectoparasites from rodents in Thailand and their sequence similarity with bacterial cultures from Thai patients. Vector-Borne and Zoonotic Diseases 10(5): 429-434. 
Kho, K., Koh, F., Jaafar, T., Hassan Nizam, Q.N. \& Tay, S-T. (2015). Prevalence and molecular heterogeneity of Bartonella bovis in cattle and Haemaphysalis bispinosa ticks in Peninsular Malaysia. BMC Veterinary Research 11: 153-162.

Kimura, M. (1980). A simple method for estimating evolutionary rate of base substitutions through comparative studies of nucleotide sequences. Journal of Molecular Evolution 16: 111-120.

Kosoy, M. \& Bai, Y. (2019). Bartonella bacteria in urban rats: a movement from the jungles of Southeast Asia to metropoles around the globe. Frontiers in Ecology and Evolution 7(88): 1-17.

Kosoy, M., Morway, C., Sheff, K.W., Bai, Y., Colborn, J., Chalcraft, L., Dowell, S.F., Peruski, L.F., Maloney, S.A., Baggett, H., Sutthirattana, S., Sidhirat, A., Maruyama, S., Kabeya, H., Chomel, B.B., Kasten, R., Popov, V., Robinson, J., Kruglov, A. \& Petersen, L.R. (2008). Bartonella tamiae sp. nov., a newly recognized pathogen isolated from three human patients from Thailand. Journal of Clinical Microbiology 46: 772-775.

Kosoy, M.Y., Regnery, R.L., Tzianabos, T., Marson, E.L., Jones, D.C. \& Green, D. (1997). Distribution, diversity, and host specificity of Bartonella in rodents from the Southeastern United States. The American Journal of Tropical Medicine and Hygiene 57: 578-588.

Kumar, S., Stecher, G. \& Tamura, K. (2016). MEGA7: Molecular Evolutionary Genetics Analysis version 7.0 for bigger datasets. Molecular Biology and Evolution 33: 1870-1874.

La Scola, B., Zeaiter, Z., Khamis, M.A. \& Raoult, D. (2003). Gene-sequence-based criteria for species definition in bacteriology: the Bartonella paradigm. Trends Microbiology 11: 318-321.

Low, V.L., Tan, T.K., Ibrahim, J., AbuBakar, S. \& Lim, Y.A. (2020). First evidence of Bartonella phoceensis and Candidatus Mycoplasma haemomuris subsp. ratti in synanthropic rodents in Malaysia. Asian Pacific Journal of Tropical Medicine 13(2): 94-96.
Maggi, R.G. \& Breitschwerdt, E.B. (2005). Potential limitations of the 16S-23S rRNA intergenic region for the molecular detection of Bartonella species. Jornal of Clinical Microbiology 43: 1171-1176.

Mardosaitè-Busaitienè, D., Radzijevskaja, J., Balčiauskas, L., Bratchikov, M., Jurgelevičius, V. \& Paulauskas, A. (2019). Prevalence and diversity of Bartonella species in small rodents from coastal and continental areas. Scientific Reports 9(12349): 1-10.

Massolo, A., Sforzi, A. \& Lovari, S. (2003). Chemical immobilization of crested porcupines with tiletamine $\mathrm{HCl}$ and zolazepam $\mathrm{HCl}$ (Zoletil) under field conditions. Journal of Wildlife Diseases 39(3): 727-731.

Mitler, T., Levy, M., Chad, F. \& Karen, S. (2010). MULTIBLAST: a web application for multiple BLAST searches. Bioinformation 5(5): 224-226.

Mohd-Taib, F.S., Mohd-Saleh, W., Asyikha, R., Mansor, M.S., Ahmad-Mustapha, M., Mustafa-Bakray, N.A., Mod-Husin, S., Md-Shukor, A., Amat-Darbis, N.D. \& Sulaiman, N. (2020). Effects of anthropogenic disturbance on the species assemblages of birds in the back mangrove forests. Wetlands Ecology and Management 28: 479-494.

Mokhtar, A.S. \& Tay, S.T. (2011). Molecular detection of Rickettsia felis, Bartonella henselae, and B. clarridgeiae in fleas from domestic dogs and cats in Malaysia. The American Journal of Tropical Medicine and Hygiene 85: 931-933.

Paziewska, A. \& Siński, E. (2011). Recombination within and between species of the alpha Proteobacterium Bartonella infecting rodents. Microbiology Ecology 61: 134-145.

Pichon, B., Rogers, M., Egan, D. \& Gray, J. (2005). Blood-meal analysis for the identification of reservoir hosts of tickborne pathogens in Ireland. Vector-Borne \& Zoonotic Diseases 5(2): 172-180.

Regier, Y., O’Rourke, F. \& Kempf, V.A.J. (2016). Bartonella spp. - a chance to establish One Health concepts in veterinary and human medicine. Parasites Vectors 9: 261-273. 
Rickart, E.A., Heaney, L.R., Balete, D.S. \& Tabaranza, B.R. (2011). Small mammal diversity along an elevational gradient in northern Luzon, Philippines. Mammalian Biology - Zeitschrift für Säugetierkunde 76(1): 12-21.

Robins, J.H., Hingston, M., Matisoo-Smith, E. \& Ross, H.A. (2007). Identifying Rattus species using mitochondrial DNA. Molecular Ecology Notes 7: 717-729.

Saisongkorh, W., Rolain, J-M., Suputtamongkol, Y. \& Raoult, D. (2009). Emerging Bartonella in humans and animals in Asia and Australia. Journal of the Medical Association of Thailand 92: 707-731.

Saitou, N. \& Nei, M. (1987). The neighborjoining method: A new method for reconstructing phylogenetic trees. Molecular Biology and Evolution 4: 406-425.

Tea, A., Alexiou-Daniel, S., Papoutsi, A, Papa, A. \& Antoniadis, A. (2004). Bartonella species isolated from rodents, Greece. Emerging Infectious Diseases 10: 963964.
Theonest, N.O., Carter, R.W., Amani, N., Doherty, S.L., Hugho, E., Keyyu, J.D. Mable, B.K., Shirima, G.M., Tarimo, R., Thomas, K.M., Haydon, D.T., Buza, J.J., Allan, K.J. \& Halliday, J.E.B. (2019). Molecular detection and genetic characterization of Bartonella species from rodents and their associated ectoparasites from northern Tanzania. PLoS ONE 14(10): e0223667.

Tsai, Y-L., Chuang, S-T., Chang, C-C., Kass, P.H. \& Chomel, B.B. (2010). Bartonella species in small mammals and their ectoparasites in Taiwan. The American Journal of Tropical Medicine and Hygiene 83: 917-923.

Walker, A.R., Bouattour, A., Camicas, J.L., Estrada Pena, A., Horak, I.G., Latif, A.A., Pegram, R.G. \& Preston, P.M. (2007). Ticks of domestic animals in Africa: a guide to identification of species. Bioscience Report: 1-221.

Yamaguti, N., Tipton, V.J., Keegen, H.L. \& Toshhioka, S. (1971). Ticks of Japan, Korea, and the Ryukyu Islands. Brigham Young University Press; p. 226. 